\title{
Developing Learning Trajectory Based Instruction of the Volume and Surface Area of the Block
}

\author{
Hongki Julie \\ Universitas Sanata Dharma \\ Yogyakarta, Indonesia \\ hongkijulie@yahoo.co.id
}

\begin{abstract}
Three components on a hypothetical learning trajectory (HLT) are (1) the learning goal, (2) the learning activities, and (3) the way of students' thinking and learning. A learning trajectory based instruction (LTBI) is defined as a teaching and learning trajectory that used HLT for instructional decisions. Although the research related to student learning in measurement of length, area and volume quite a lot, but the research related to student learning in connection between the measurement of length, area and volume is still relatively small. The researcher tried to develop a context which helps students to construct the formula of the volume and the surface area of block. In this paper, the researcher will present about the LTBI for grade five students about the volume and the surface area of the block used RME approach. According to Two methods to find the volume of the three-dimensional figure are (1) the space is packed with a three-dimensional array unit which is iterated in the three-dimension and we called as the packing method, and (2) the space is filled by iterating a fluid unit which takes the shape of the container and we called as the filling method. The method chosen by researcher to find the volume of block in this paper is the packing method. The type of the research used by the researcher in this study is the design research developed by Gravemeijer and Cobb. According to Gravemeijer and Cobb, there are three phases in the research development, namely (1) the preparation of the design, (2) testing the design, and (3) the retrospective analysis. The researcher' exposure in this paper is limited to the first stage of the design research developed by Gravemeijer and Cobb.
\end{abstract}

Keywords- Hypothetical Learning Trajectory, Learning Trajectory Based Instruction, Realistic Mathematics Education (RME), The Packing Method.

\section{INTRODUCTION}

Reference [1] indicated errors made by grade $5-8$ students in the volume measurement tasks using unit cubes are associated with some aspects of visualizing spatial abilities, such as the ability to "read" a two-dimensional representation of a geometrical object. In the study, students are asked to determine many unit cubes in a block that is presented in the two-dimensional image form (the sample question given to students can be seen in figure 1).
10. How many cubes are needed to build this rectangular solid?

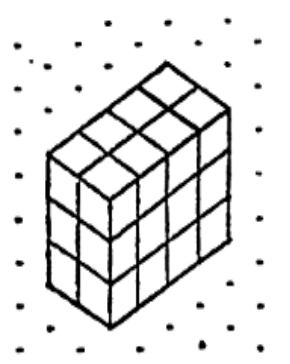

$\begin{array}{ccccc}A & B & C & D & E \\ 18 & 24 & 26 & 36 & 52\end{array}$

Fig 1. One of the questions that were developed by [1]

The choices in the test show the students' strategy in determining many unit cubes that form a block. Reference [1], there are four strategies producing the wrong answer which may be done by the students, namely:

1. If the students calculated the number of square shown in the picture on the test, then they will choose the option $\mathrm{C}$.

2. If the students calculated the number of square shown in the picture on the test and doubled it, then they will choose the option E.

3. If the students counted the number of the cube unit shown in the picture, then they will choose the option A.

4. If the students counted the number of the cube unit shown in the picture and doubled it, they will choose the option D.

The problem type such as those developed by [1] also developed in Indonesia. This problem type is generally used to introduce the concept of the block volume and the cube volume as can be seen in figure 2. The researcher tried to interview three of 5th grade teachers in Yogyakarta to ask what mistakes are generally made by the students if they are given problems like in the figure 1 . From the interview, the researcher is able to conclude that the common mistakes made by students in the grade 5 of elementary school are that they calculated the number of the square shown in the picture on the test and counted the number of the cube unit shown in the figure 2 . 


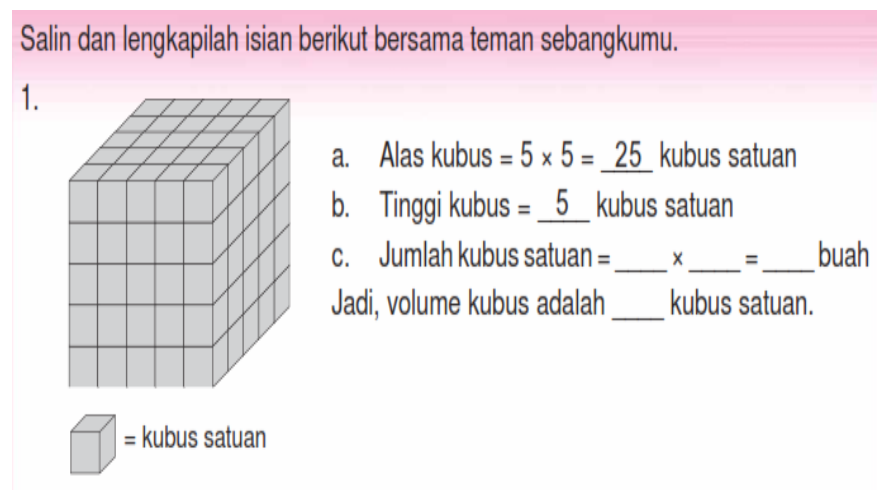

Fig 2. The example of a finding volume problem in the grade 5 elementary school textbook [2]

\section{THEORETICAL FRAMEWORK}

Simon is the first researcher using the term hypothetical learning trajectory (HLT) to represent the students' learning process from their prior knowledge until the learning objective is set by the teacher [3]. Reference [4] states that there are three components on a HLT, i.e.: (1) the learning goal, (2) the learning activities, and (3) the way of students' thinking and learning. Reference [4] names a trajectory as a hypothetical learning trajectory because the student's learning trajectory is unknownable.

According to Romber and Carpenter (1986 in [3]) the learning and the teaching are often seen as two sides of the same phenomenon, but often the studies carried out in these two areas are not connected to one another. One attempt to connect the research in both fields appeared in 2012 conducted by [3]. Their effort to combine research in both areas is to construct what they referred to as learning trajectory based instruction (LTBI). A LTBI is defined as a teaching and learning trajectory that HLT used for instructional decisions [3].

Reference [5], the volume can be found in two ways, namely:

1. The filling method which is filled the space object with liquid.

2. The packing method which is filled the space with other objects is smaller in size and had the same shape and size.

Reference [5], if the teacher knew about the development stage of students' conceptual understanding in the measurement of length, area, and volume, then teachers will be able to teach these topics.

The philosophy of RME is mathematics as a human activity. It meant learning mathematics should be able to make the students think that there is mathematics in human activities, and it is be used by them in real life [6]. So, the learning process of mathematics first of all should not be connected with mathematics as a deductive system that is well organized and formal, but it should be connected with mathematics as a human activity (Freudenthal, 1971, 1973, in [7). If the mathematics learned by the studentd is connected to a formal deductive system, then they will view that mathematics is resulted by the human thinking; it is an abstract thing and is not related to real-life. So, they will think that they cannot find mathematics and using mathematics in their life [6]

There are five main characteristics in the RME [7], [8] namely:

1. phenomenological exploration;

2. bridging by vertical instruments;

3. student contributions;

4. interactivity;

5. intertwining.

Reference [9] design research can be characterized as:

1. Iterventionist: the research leading to the design of an intervention in the real world.

2. Iterative: the research incorporates a cyclic approach to the design, evaluation, and revision.

3. Process-oriented: a model of research that avoids the measurement of inputs and outputs, focus on understanding and improving interventions.

4. Oriented to usability: the benefits of design are measured by looking at the practicality of the design for the user in reality.

5. Oriented to the theory: design (at least partially) made by theories that already exist, and field testing of the design contribute to the development of the theory.

According Gravemeijer and Cobb in [9] there are three phases in the design research, namely:

1. The first phase: preparation of trial design.

2. The second phase: trial design.

3. The third phase: a retrospective analysis.

\section{METHOD}

The type of the research used in this study is the research design developed by Gravemeijer and Cobb. Results of study presented in this paper are the first phase results. In this phase, the researcher conducted the following activities:

1. Assessing basic competencies already possessed by students before the students learnt about the volume and the surface area of the block based on the revised curriculum of 2013.

2. Reviewing basic competencies that students needed to have associated with the volume and the surface area of the block based on the revised curriculum of 2013 .

3. Developing the hypothetical learning trajectory about the volume and surface area of the block using RME approach.

4. Developing the LTBI about the volume and surface area of the block using RME approach. 


\section{RESULTS AND DISCUSSION}

The assessment on the students' prior basic competencies is that the students have learnt about the volume and the surface area of the block based on the revised curriculum of 2013. The results are as follows:

\section{1) Grade 1:}

a) Knowing two-dimensional and three-dimensional figure through a variety of concrete objects.

b) Classifying two-dimensional and three-dimensional figure based on a certain property through a variety of concrete objects.

c) Knowing and determining the length with the non standard unit using concrete objects or situations.

d) Measuring the length of the object with the non standard unit using concrete objects or situations.

e) Comparing the length of some objects using concrete objects or situations.

f) Ordering some objects based on the length.

2) Grade 2:

a) Explaining and determining the length (including the distance) on the standard unit and related to daily life.

b) Measuring the length of the object (including the distance) on the standard unit and related to daily life.

c) Explaining two-dimensional and three-dimensional figure based on their characteristics.

d) Classifying two-dimensional and three-dimensional figure based on their characteristics.

3) Grade 3:

a) Describing and determining the relationship between the standard units of length which are commonly used in daily life.

b) Solving the problem related the relationship between the standard units of length which are commonly used in daily life.

c) Explaining and determining the area and volume on the non-standard unit using concrete objects.

d) Solving the problem related the area and volume on non-standard units using concrete objects.

4) Grade 4:

a) Explaining and determining the common factor, the greatest common factor (GCF), common multiple, and least common multiple (LCM) on two numbers related to daily life.

b) Solving the problem related to the common factor, the greatest common factor (GCF), common multiple, and least common multiple (LCM) on two numbers related to daily life. c) Explaining and determining the circumference and the area of the square, and rectangle.

d) Solving the problem related to the circumference and the area of the square, and rectangle.

The reviewing basic competencies that students needed to have associated with the volume and the surface area of the block based on the 2013 revision curriculum are as follows:

\section{1) Grade 5:}

a) Explaining and determining the volume of the threedimensional figure using the volume unit (such as cube unit).

b) Solving the problem the volume of the threedimensional figure using the volume unit (such as cube unit).

c) Explaining and finding the nets of the simple threedimensional figure (such as cube and block).

d) Making the nets of the simple three-dimensional figure (such as cube and block).

2) Grade 8:

a) Differentiating and determining the surface area and the volume of the flat side three-dimensional figure (such as cube, block, prism, and pyramid).

b) Solving problem related to the surface area and the volume of the flat side three-dimensional figure (such as cube, block, prism, and pyramid) and the combination of them.

\subsection{The Learning Trajectory Based Instruction (LTBI)}

Indicators of the teaching and learning process:

a) Students can reinvent the volume definition and the volume formula of a block and a cube.

b) Students can apply the volume definition and the volume formula of the block and cube to solve problems.

c) Students can reinvent the surface area definition and the surface area formula of the block and the cube.

d) Students can apply the surface area definition and the surface area formula of the block and the cube to solve problems.

2) The activities of a teacher and students:

a) Activities to construct social norms in the classroom.

The teacher provided the social norms that will be set up in the classroom, namely:

1) If a student wants to inquire, express his or her opinion, answer questions, or provide feedback on an opinion from the other students, then the student need to lift his or her hand first, and the student can start talking when the teacher has given him or her the chance to speak. 
2) If there is a student who is expressing his or her opinion, then the other students will hear his or her opinion.

3) If the teacher ask the students about their answers, then it does not mean their answers are incorrect, but the teacher wants to know how the student is thinking.

b) The problem exploration

1) Students are shown a pack of candy. It contains 10 grains of candy, but the students cannot know the number of candies in the pack.

2) Students are given the following problem: estimate "how many candies are in the pack?" This is an attempt to bring out the phenomenological exploration characteristics of RME.

3) To help students estimate the number of candies in the pack, the teacher can open a part of the candy wrappers, so they can look at two or three candies on the pack. This is an attempt to bring out the bridging by vertical instruments characteristics of RME.

4) The students are given time to discuss in a pair. This is an effort to bring out the interactivity characteristics of RME.

c) The class discussion

1) One student is asked by the teacher to explain to other students about what his or her strategy used to determine the number of candies in one pack. There are four possible ways expressed by the student, namely:

a) The Student measures the thickness of one candy and the pack of candy using a ruler or other measuring devices. After that, the student calculates the number of candies in the one pack to be the same as the length of a pack of candies divided by the thickness of one candy.

b) The student measures the thickness of two candies and the pack of candies using a ruler or other measuring devices. After that, the student calculates the number of candies in the one pack to be the same as the length of a pack of candies divided by the thickness of one candy and then multiplied by 2 .

Note: each solution process made by the students for this problem in the RME is referred to as a model. This is an effort to bring out the students contributions of characteristics of RME.

2) Other students are asked to respond to what is presented by the student.

3) Teacher asks the other students who have different strategies to convey the idea.

4) Other students are asked to respond to what is presented by the student.
5) The teacher conducts a class discussion and guides the discussion so that students can gain the number of candies in a pack and understand that the volume of the three-dimensional figure (in mathematics) has the same meaning as the content of the threedimensional figure (in the daily language). In this context, the content of one pack of candies represents the volume of a block.

d) The problem of exploration

1) Students are asked to discuss in a pair about whether there is any other form of packaging that can be made to pack 10 candies.

2) The teacher can provide a number of units of cubes (instead of candy) to each pair to help the students in exploring the problem.

e) The class discussion

1) One student asked by the teacher to explain to other students, how other form of packaging can be made to pack 10 candies. There are six possible ways expressed by the students, namely:

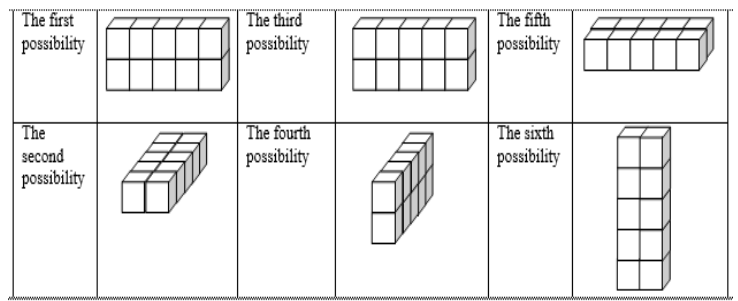

Other students are asked to respond to what is presented by the student.

2) The teacher handles the class discussion and guides the discussion so that the students can see that the content of the pack of candies are 10, all these possibilities are the same thing instead of if returned to the context of the form of candy packaging, and the form of the packaging is different from the first candy packaging. This is an attempt to bring out the bridging by vertical instrument characteristics of RME.

f) The problem of exploration

1) Students are required to solve the following problem in a pair if they want to pack 10 candies. The teacher ask them "how much minimum paper do you need to pack 10 candies?".

2) The teacher can provide a number of unit of cubes (instead of candy) to each pair to help their students in exploring the problem.

3) If the students have difficulty, they can be helped by the following process:

a) Students are asked the number of sides in the candy packaging. 
b) If the students can answer, then they are asked the number of sides that have the same molded sides in the candy packaging.

c) If students can answer, they are asked the form of each side of the candy packaging.

d) If students can answer, they are asked the way to find the area of the side.

e) If the students can answer, they are asked the way to find the area of paper required to pack the one candy packaging.

g) The class discussion

1) One pair of students is asked by the teacher to explain to other students, "how do they solve the problems?"

The students' possible answers are as follows:

Suppose the length of the side of each unit of cube is 1 unit of length.

If the packaging is made in the form below:

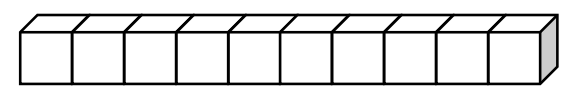

The minimum paper that needed to pack 10 candies $=(4 \times 10 \times 1)+(2 \times 1 \times 1)=40+2=42$ unit area. If the packaging is made in the form below:

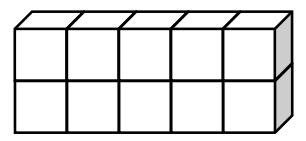

The minimum paper needed to pack 10 candies is $=$ $(2 \times 5 \times 1)+(2 \times 5 \times 2)+(2 \times 1 \times 2)=10+20+4$ $=34$ wide units.

Thus, the minimum paper needed to pack 10 candies is the second packaging.

2) Other students are asked to respond to what is presented by the student.

3) The teacher handles the class discussion and guides the discussion so that students can see that the area of packaging needed to pack every form of the packaging is $(2 \times$ length $\times$ width $)+(2 \times$ length $\times$ height $)+(2 \times$ width $\times$ height $)$. This is the formula for the surface area of the block.

This is an attempt to bring out the bridging by vertical instruments with characteristics of RME.

h) The problem of exploration

1) Students are asked to discuss the following problem in a pair if a company wants to make candy packaging in which one pack contains 24 candies, then what is the shape of candy packaging that may be made by the company and which one needs the minimum paper packaging.
2) The teacher can provide 24 units of cubes (instead of candy) in the teacher's desk or provide help with providing the laptop with Microsoft Windows on the desk in exploring the problem. The teacher cab draw 24 units of cubes by using the program and students can try to make the candy packaging.

i) The class discussion

1) One student is asked by the teacher to explain to other students about the way to solve the problem. There are six possible ways expressed by students, namely:

TABLE I. SIX POSSIBLE WAYS EXPRESSED BY STUDENT

\begin{tabular}{|c|c|c|c|c|}
\hline Possibility & Length & Width & Height & $\begin{array}{c}\text { The Paper } \\
\text { Packaging } \\
\text { Area }\end{array}$ \\
\hline \multirow[t]{3}{*}{ First } & 1 & 1 & 24 & \multirow{3}{*}{98} \\
\hline & 1 & 24 & 1 & \\
\hline & 24 & 1 & 1 & \\
\hline \multirow[t]{6}{*}{ Second } & 1 & 2 & 12 & \multirow[t]{6}{*}{76} \\
\hline & 1 & 12 & 2 & \\
\hline & 2 & 1 & 12 & \\
\hline & 2 & 12 & 1 & \\
\hline & 12 & 2 & 1 & \\
\hline & 12 & 1 & 2 & \\
\hline \multirow[t]{6}{*}{ Third } & 1 & 3 & 8 & \multirow[t]{6}{*}{70} \\
\hline & 1 & 8 & 3 & \\
\hline & 3 & 1 & 8 & \\
\hline & 3 & 8 & 1 & \\
\hline & 8 & 1 & 3 & \\
\hline & 8 & 3 & 1 & \\
\hline \multirow[t]{6}{*}{ Fourth } & 1 & 4 & 6 & \multirow[t]{6}{*}{68} \\
\hline & 1 & 6 & 4 & \\
\hline & 4 & 1 & 6 & \\
\hline & 4 & 6 & 1 & \\
\hline & 6 & 1 & 4 & \\
\hline & 6 & 4 & 1 & \\
\hline \multirow[t]{3}{*}{ Fifth } & 2 & 2 & 6 & \multirow[t]{3}{*}{40} \\
\hline & 2 & 6 & 2 & \\
\hline & 6 & 2 & 2 & \\
\hline \multirow[t]{6}{*}{ Sixth } & 2 & 3 & 4 & \multirow[t]{6}{*}{52} \\
\hline & 2 & 4 & 3 & \\
\hline & 3 & 2 & 4 & \\
\hline & 3 & 4 & 2 & \\
\hline & 4 & 2 & 3 & \\
\hline & 4 & 3 & 2 & \\
\hline
\end{tabular}

2) Other students are asked to respond to what is presented by the student.

3) The teacher handles class discussion and guides the discussion so that (a) students can view each event in each possibility in the same thing. It is not something different if we return to the packaging candy context, (b) the students can see that the packaging shape in every possibility is different from each other, (c) students can find that the number of the candy in each package is the number of the candy that make up the length of the packaging multiplied by the number of the candy that make up the width of the packaging multiplied by the number of the candy that make up the high of the packaging, and (d) the minimum paper 
packaging is happened if the packaging shaped will like a fifth possibility.

This is an attempt to bring out the bridging by vertical instruments characteristics of and the student contributions characteristics of RME.

4) The teacher draws one of the possibilities, for example taken that length of 8 units, the width of 3 units, and the height of 1 unit. The image obtained is as follows:

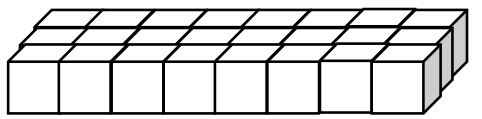

5) Students are asked to answer the following question if the contents of the candy packaging like in the picture that I created, "how many candies are there in one packaging?"

6) The teacher discusses this question in the classical situation so that students realize that the number of the candies in one package are 24 candies. It is necessary for the teacher to maka the students realize that the picture is a two-dimensional image, so no all of the cubes representing candies can be seen fully as a cube. This activity is intended for students to have the ability to "read" a twodimensional representation of a three-dimensional object.

j) The problem of exploration

1) Students are required to solve the following problems:

Write the name, the volume, and the surface area of each three-dimensional object below!

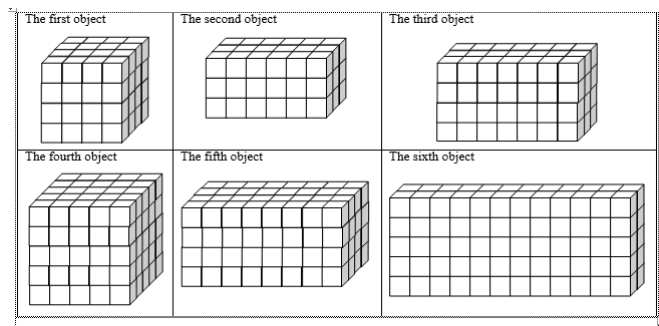

2) If there are students who have difficulty in solving the problems, the teacher may ask the student to build the three-dimensional object from the picture by using unit cubes. After that, students are asked to calculate the number of unit of cubes that they needed to build the threedimensional object.

3) If the students still count one by one when they find the number of the unit cubes that build the three-dimensional object, then the teacher will help the student. The way that can be used by the teacher to help the student is as followed:

a) The students are asked to build the first stage of the three-dimensional object using unit cubes. b) The teacher asked the number of units of cubes you need to build up the first level of this object without counting one by one.

c) The teacher guides the students so that the students can find the number of units of cubes necessary to build the threedimensional object, namely: the number of the units of length multiplied by the number of the units of width.

d) The students are asked the number of levels of the object.

e) If the students can answer this question, students are asked about the number of units of cubes needed to build the threedimensional object.

f) The teacher guides the students so that they can find the number of units of cubes needed to build object, namely: the number of the length unit multiplied by the number of the width unit multiplied by the number of the high unit.

k) The group discussion and class discussion

1) If students finish in solving these problems, the students are required to discuss the results obtained with a seatmate.

2) The teacher asked six pairs to write down the discussion results that they got. Each student writes one solution for one problem.

3) The expected answers are as follows:

The first object is a cube. The volume of the object is $4 \times 4 \times 4=64$ units of volume, and the surface area of the object is $6 \times 4 \times 4=96$ units.

The second object is a block. The volume of the object is $6 \times 3 \times 3=54$ units of volume, and the surface area of the object is $(4 \times 3 \times 3)+(2 \times 6 \times 3)$ $=36+36=72$ units.

The third object is a block. The volume of the object is $7 \times 3 \times 4=84$ units of volume, and the surface area of the object is $(2 \times 7 \times 3)+(2 \times 7 \times 4)$ $+(2 \times 3 \times 4)=42+56+24=122$ units.

The fourth object is a cube. The volume of the object is $5 \times 5 \times 5=125$ units, and the surface area of the object is $6 \times 5 \times 5=150$ units.

The fifth object is a block. The volume of the object is $8 \times 4 \times 4=128$ units, and the surface area of the object is $(4 \times 4 \times 4)+(2 \times 8 \times 4)=64+64=128$ units.

The third object is a block. The volume of the object is $12 \times 2 \times 5=120$ unit, and the surface area of the object is $(2 \times 12 \times 2)+(2 \times 12 \times 5)+(2 \times 2$ $\times 5)=48+120+20=188$ units. 
4) Other students are asked to respond to what is presented by the student.

5) The teacher handles the class discussion and guides the discussion so that students can use their findings earlier about the number of units of cubes needed to build object, namely: the number of the length units multiplied by the number of the width units multiplied by the number of the hight units and the students can write down the volume of the cube $=$ the length of the side $x$ the length of the side $x$ the length of the side and the volume of the block $=$ the lenght of the length $\times$ the length of the width $\times$ the length of the height. In addition, students are expected also to be able to write down the surface area of the cube $=6 \times$ the length of the side $\times$ the length of the side, and the surface area of the block $=2 \times$ (the long of the length $\times$ the length of the width + the length of the length $\times$ the length of the height + the lenght of the width $\times$ the length of the height).

This is an attempt to bring out the bridging by characteristics of vertical instruments and the students' characteristics of contributions of RME.

1) The problem of exploration

1) Students are required to solve the following problem:

Determine the volume and surface area of these blocks.

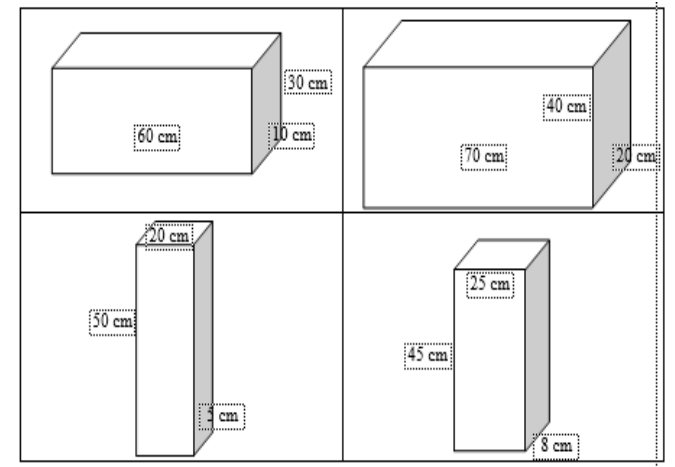

2) If students still have difficulty to understand how to calculate the volume and the surface area of the block, the teacher can help by giving the following question: If the unit cube of the length, width, and height is $1 \mathrm{~cm}$, then "how many unit cubes are needed to make up the length, width, and height of the blocks in the above problems?'. If the students can answer this question, then students are asked "how many unit cubes are needed to fill the blocks in the problem.

m) The group discussion and class discussion

1) If students finish in solving these problems, the students are required to discuss the results obtained with a seatmate.
2) The teacher asks four pairs to write down the discussion results that they got. Each student writes one solution for one problem.

3) The expected answer is as follow:

The volume of the first block is $60 \times 10 \times 30=$ $18000 \mathrm{~cm}^{3}$, and the surface area of first block is $(2 \times 60 \times 10)+(2 \times 60 \times 30)+(2 \times 10 \times 30)$ $=1200+3600+600=5400 \mathrm{~cm}^{2}$.

The volume of the second block is $70 \times 20 \times 40$ $=56000 \mathrm{~cm}^{3}$, and the surface area of the second block is $=(2 \times 70 \times 20)+(2 \times 70 \times 40)+(2 \times$ $20 \times 40)=2800+5600+1600=10000 \mathrm{~cm}^{2}$.

The volume of the third block is $20 \times 5 \times 50=$ $5000 \mathrm{~cm}^{3}$, and the surface area of the third block is $(2 \times 20 \times 5)+(2 \times 20 \times 50)+(2 \times 5 \times$ 50) $=200+2000+500=2700 \mathrm{~cm}^{2}$.

Volume beams fourth $=25 \times 8 \times 45=9000$ $\mathrm{cm} 3$, and the surface area of the beam four $=(2$ $\times 25 \times 8)+(2 \times 25 \times 45)+(2 \times 8 \times 45)=400+$ $2250+720=3370 \mathrm{~cm} 2$.

4) Other students are asked to respond to what is presented by the student.

5) The teacher handles class discussion and guides the discussion so that students can use their previous findings, to solve these problems.

This is an attempt to bring out the bridging by characteristics of vertical instruments and the students' characteristics of contributions of RME.

\section{CONCLUSIONS}

There are four conclusions can be made from the above explanation, namely:

1. The method used by the researcher in helping students to construct the meaning of the block and cube volume is the packing method.

2. The context developed by the researcher in LTBI to aid students in constructing the meaning of the block and cube volume and the way to find the block and cube volume is to determine the number of the candy in one pack and the packaging shapes that can be formed to pack the number of the candies.

3. The context developed by the researcher in LTBI to help students in constructing the meaning of the block and cube surface area and the way to find of the block and cube surface area is to calculate the minimum paper packaging area required to pack one candy packaging.

4. To improve LTBI that has been developed by the researcher in this paper, the researcher still needs to try out the LTBI in the real class. 


\section{REFERENCES}

[1] D. Ben-Haim, G. Lappan and T. Houang, "Visualizing rectangular solids made of small cubes: analyzing and effecting students' performance," Educational Studies in Mathematics, vol. 16, pp. 389-409, 1985.

[2] Y. D. Sumanto, H. Kusumawati and N. Aksin, Gemar Matematika 5, untuk Kelas V SD/MI, Jakarta: Pusat Perbukuan Departemen Pendidikan Nasional , 2008.

[3] P. Sztajn, J. Confrey, P. H. Wilson and C. Edgington, "Learning trajectory based instruction: toward a theory of teaching," Educational Researcher, vol. 41, no. 5, pp. 147-156, 2012.

[4] M. A. Simon, "Reconstructing mathematics pedagogy from a constructivist perpective," Journal of Research in Mathematics Education, vol. 26, no. 114-145, 1995.

[5] M. Curry and L. Outhred, "Conceptual Understanding of Spatial Measurement. In P. Clarkson, A. DOwnton, D. Gronn, A. McDOnough, R. Pierce and A. Roche (Eds). Building Connections: Theory, Research, and Practice," in Proceedings of The 28th Annual Conference of Mathematics Education Research Group of Australia, Melbourne, Sydney, 2005.

[6] H. Julie, "Developing Student Learning Materials on Multiplication Fraction for Grade Five with Realistic Mathematics Education," in Proceedings of the 4th SEA-DR Conference, Padang, 2016.

[7] K. P. G. Gravemeijer, Developing Realistic Mathematics Education, Utrecht: Freudenthal Institute, 1994.

[8] H. Julie, "Studnet Learning on the Multiplication and Division of Fractions for Grade Five with Realistic Mathematics Education," in Proceedings of the 3th SEA-DR Conference, Palembang, 2015.

[9] J. V. D. Akker, K. Gravemeijer, S. McKenney and N. Nieveen, Educational Design Research, New York: Taylor and Francis Group, 2006. 